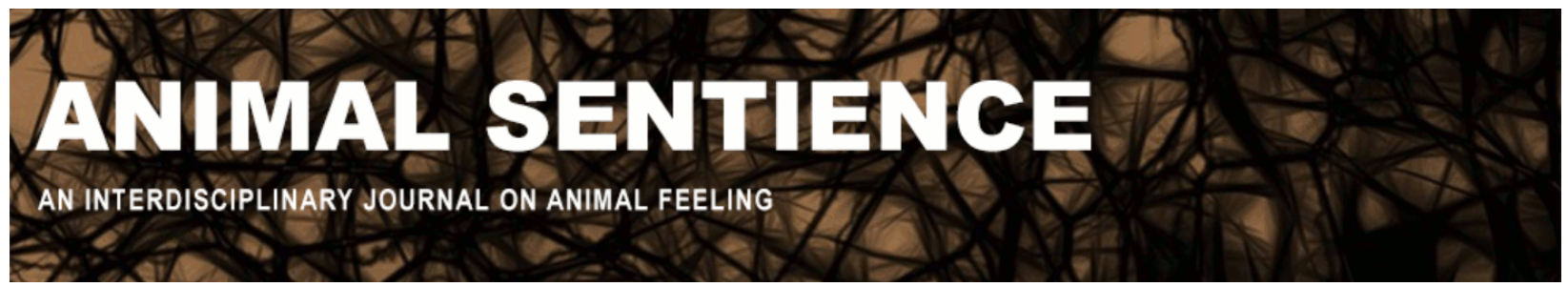

Feyten, Laurence E. A. and Brown, Grant E. (2018) Ecological uncertainty influences vigilance as a marker of fear. Animal Sentience 15(7)

DOI: $10.51291 / 2377-7478.1311$

Date of submission: 2018-02-18

Date of acceptance: 2018-02-26

(c)

This article has appeared in the journal Animal

Sentience, a peer-reviewed journal on animal

cognition and feeling. It has been made open access,

free for all, by WellBeing International and deposited

in the WBI Studies Repository. For more information,

please contact

wbisr-info@wellbeingintl.org.

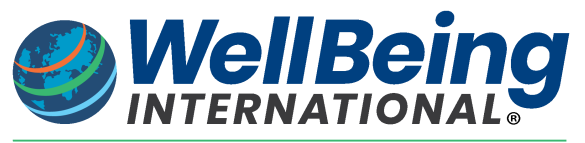

SOLUTIONS FOR PEOPLE, ANIMALS AND ENVIRONMENT 


\title{
Ecological uncertainty influences vigilance as a marker of fear
}

Commentary on Beauchamp on Fear \& Vigilance

\author{
Laurence E. A. Feyten \\ Concordia University, Montreal
}

Grant E. Brown

Concordia University, Montreal

\begin{abstract}
We expand on the factors that may shape the predictability of risk and the potential impacts on the links between vigilance and fear, primarily in aquatic prey communities. Uncertainty in predation risks has been shown to induce increased levels of neophobia among prey. As a result of this phenotypically plastic response, prey are faced with risk assessment cues that may vary widely in their reliability. We argue that decomposing predictability may provide useful insights into the relationship between vigilance and fear.
\end{abstract}

Laurence E. A. Feyten is a doctoral candidate in the Department of Biology, Concordia University. She is examining the effects of the uncertainty of public information use on the form and intensity of phenotypically plastic neophobia in Trinidadian guppies.

www.researchgate.net/profile/Laurence Feyten

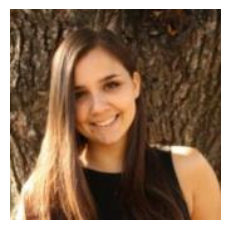

Grant E. Brown is a Behavioural and Cognitive Ecologist in the Department of Biology, Concordia University, focusing on aquatic prey species. Combining laboratory and field experiments, he explores the tactics employed by prey to optimize behavioural decisions under conditions of ecological uncertainty.

sites.google.com/site/brownlabhome/

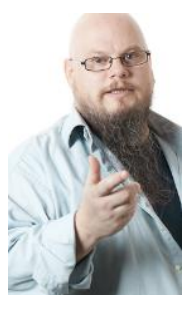

In his target article, Beauchamp (2017) explores the links between vigilance (an observable behaviour) and fear (an underlying 'state') among prey animals. One factor that Beauchamp suggests might lead to the decoupling of 'vigilance' and 'fear' is the predictability of risk. Focusing primarily on the aquatic literature, we expand on this question and argue that it is a potentially fruitful area of research.

A growing body of research highlights the impact of the spatial and/or temporal variability in predation threats and how this leads to uncertainty amongst prey populations (Lima \& Bednekoff 1999; Brown et al. 2013). Ecological uncertainty can be defined as ambiguity about the state of the environment due to incomplete information (Dall et al. 2005; Munoz \& Blumstein 2012). It is well-established that prey that can reliably assess local risks are better able to balance the conflicting demands of predator detection and avoidance and a suite of other activities such 
as foraging, mating, and territorial defense (Lima \& Dill 1990; Sih 1992). In the absence of reliable information regarding local risks, however, prey should 'overestimate' the degree of risk (Brown et al. 2014). Responding to non-relevant cues or situations would result in lost opportunities, for example, to forage. However, failing to respond to a relevant threat may result in death. As a result of these asymmetric costs, prey are expected to 'err on the side of caution' when faced with uncertain conditions (Johnson et al. 2013; Ferrari et al. 2018).

How then do prey cope with ecological uncertainty? Initially, prey can reduce uncertainty through the accumulation of direct and indirect experience (i.e., learning; Dall et al. 2005; Schmidt 2010). As a result of acquired information, they should be better able to reliably assess risks and optimize behavioural decisions (Brown et al. 2011). This has been particularly well-studied in prey fishes (Brown 2003; Ferrari et al. 2010). For example, a wide variety of aquatic prey can recognize predator cues when they are paired with damage-released alarm cues (a reliable and honest indicator of local risks; Ferrari et al. 2010; Brown et al. 2011). However, learning is itself costly, as prey must survive the initial interaction with a potential predator in order to accumulate relevant experience (Ferrari et al. 2007). We have argued that phenotypically plastic neophobia (broadly defined as the avoidance of any novel stimulus) may function as an adaptive response to ecological uncertainty, reducing the short-term costs of learning among prey populations (Brown et al. 2013). For example, Trinidadian guppies (Poecilia reticulata) from high but not low predation populations exhibit increased predator avoidance (Brown et al. 2013) and latencies to explore novel foraging patches (Elvidge et al. 2016) in the presence of novel cues. Indeed, exposure to elevated risks, even over a period of a few days, is sufficient to induce neophobic responses in a variety of aquatic prey (Brown et al. 2013; 2015).

Thus, prey are faced with risk assessment of information that varies in reliability. A cue is reliable when it is consistently correlated with immediate predation risk (Searcy \& Nowicki 2005); therefore, known cues (i.e., damage-release alarm cues or cues learned via direct experience) may be more reliable than unknown (i.e., neophobic) cues. The variable reliability of information may influence the apparent correlation between vigilance and the underlying physiological correlates. Beauchamp outlines four potential cases determining whether vigilance is a good marker of fear. In cases 2 and 3, vigilance and physiological correlates decouple; Beauchamp relates this to the predictability of risk in a prey's 'landscape of fear'. We might predict that the link between vigilance and fear is a function of ecological uncertainty and reliability of a cue (Table 1). Hence uncertainty, coupled with the reliability of information, may play an important role in determining whether vigilance is a good marker of fear. Below, we outline how vigilance and physiological correlates of fear will be influenced by uncertainty.

\begin{tabular}{|c|c|c|}
\hline \multirow[b]{2}{*}{ Risk } & \multicolumn{2}{|l|}{ Environment } \\
\hline & Certain & Uncertain \\
\hline Known & Vigilance increases & Vigilance increases \\
\hline & Physiological correlates decrease & Physiological correlates decrease \\
\hline Unknown & $\begin{array}{l}\text { Vigilance decreases } \\
\text { Physiological correlates decrease }\end{array}$ & $\begin{array}{l}\text { Vigilance increases } \\
\text { Physiological correlates increase }\end{array}$ \\
\hline
\end{tabular}


Initially, habitats or patches in which prey have adequate foraging opportunities and are exposed to a stable predator guild can be considered as having low degrees of uncertainty. Under such conditions, risk cues are more likely to be known, providing reliable information to prey (Brown et al. 2011). Prey could optimize behavioural trade-offs by responding only to known information and ignoring unknown cues as unlikely to represent acute risks. However, as the predictability of resources and predation decreases, prey would potentially benefit from increasing vigilance towards novel cues (i.e., neophobia; Brown et al. 2013). In fact, uncertainty may have an additive effect on avoidance by prey. Trinidadian guppies respond with predator avoidance to cues of mixed reliability, but over-estimate risk when both sources of information are unreliable (Feyten et al. unpublished data). Likewise, guppies exposed to different levels of background predation had a graded response to known risky cues, but an elevated, non-graded avoidance response to a novel cue (Brown et al. 2014). In addition, guppies tested in pools with high micro-habitat complexity were more neophobic (i.e., vigilant) than guppies tested in lowcomplexity pools (Feyten \& Brown unpublished data).

We might likewise expect the interacting effects of ecological uncertainty and reliability of information to be drivers of stress responses. Ecological stressors (i.e., predation, food deprivation) can be acute or chronic (i.e., shorter- vs. longer-term; Boonstra 2013; Cyr \& Romero 2006). Boonstra, however, suggests that prey may show a chronic stress response to acute threats when those threats are unpredictable. As a result of this unpredictability, prey may develop anticipatory memory of the attack, enhancing vigilance and increasing fear. We might expect any form of ecological uncertainty and the resulting reliability of risk assessment information to similarly influence the decoupling of vigilance and fear. When prey are exposed to reliable (or known) cues in predictable environments, we expect them to have only a short-term stress response to risks. For example, Belding's ground squirrels (Spermophilus beldingi) experiencing predictable high-risk habitats had lowered stress hormone levels (compared to those facing low risks), suggesting the ability to mount a stress hormone response and consequently a quick behavioural response (Mateo 2007). Similarly, if the risk assessment information is known but the habitat is uncertain, we expect a tempered intensity of the stress response. Thus, knowledge of available information may counter Boonstra's predicted effects of uncertainty.

Alternatively, prey may face unreliable cues. Analogous to the previous example, we expect the effects of predictable environments to counter the effects of unknown risk assessment information. When an unknown cue is perceived in a predictable environment, we expect no increase in physiological correlates of fear. The reasoning is that the costs of a stress hormone response (depleting energy stores) might be greater than any potential benefits. However, when the environment is unpredictable and the cue is unknown, we expect these two sources of uncertainty to have synergistic effects, resulting in the large chronic response suggested by Boonstra. Consequently, we expect the benefits associated with a stress hormone response to outweigh the costs until prey learn to reliably associate specific risks with novel cues.

As argued by Beauchamp, predictability may lead to the decoupling of 'vigilance' and 'fear'. We argue here that predictability is itself a product of ecological uncertainty and the reliability of public information. Given that ecological uncertainty is predicted to increase as a result of the combined effects of climate change, anthropogenic habitat loss and/or invasive species, how prey populations respond to uncertainty and its effects on information is fast becoming a pressing question. 


\section{References}

Beauchamp, G. (2017). What can vigilance tell us about fear? Animal Sentience 15(1).

Boonstra, R. (2013). Reality as the leading cause of stress: Rethinking the impact of chronic stress in nature. Functional Ecology, 27: 11-23.

Brown, G. E. (2003). Learning about danger: Chemical alarm cues and local risk assessment in prey fishes. Fish and Fisheries, 4: 227-234.

Brown, G. E., Elvidge, C. K., Ramnarine, I., Chivers, D. P. \& Ferrari, M. C. O. (2014). Personality and the response to predation risk: Effects of information quantity and quality. Animal Cognition, 17(5): 1063-1069.

Brown, G. E., Elvidge, C. K., Ramnarine, I., Ferrari, M. C. O. \& Chivers, D. P. (2015). Background risk and recent experience influences retention of neophobic responses to predators. Behavioral Ecology and Sociobiology, 69: 737-745.

Brown, G. E., Ferrari, M. C. \& Chivers, D. P. (2011). Learning about danger: Chemical alarm cues and threat-sensitive assessment of predation risk by fishes. In C. Brown, K. Laland \& J. Krause (Eds.), Fish Cognition and Behaviour (pp. 59-74). Oxford: Blackwell.

Brown, G. E., Ferrari, M. C. O., Elvidge, C. K., Ramnarine, I. \& Chivers, D. P. (2013). Phenotypically plastic neophobia: A response to variable predation risk. Proceedings of the Royal Society $B$, 280: 20122712.

Cyr, N. E. \& Romero, L. M. (2009). Identifying hormonal habituation in field studies of stress. General and Comparative Endocrinology, 161: 295-303.

Dall, S. R., Giraldeau, L. A., Olsson, O., McNamara, J. M. \& Stephens, D. W. (2005). Information and its use by animals in evolutionary ecology. TRENDS in Ecology and Evolution, 20(4): 187193.

Elvidge, C. K., Chuard, P. J. C. \& Brown, G. E. (2016). Local predation risk shapes spatial and foraging neophobic patterns in Trinidadian guppies. Current Zoology, 62(5): 457-462.

Ferrari, M. C. O., Brown, G. E. \& Chivers, D. P. (2018). Understanding the effect of uncertainty on the development of neophobic antipredator phenotypes. Animal Behaviour, 136: 101-106.

Ferrari, M. C. O., Gonzalo, A., Messier, F. \& Chivers, D. (2007). Generalization of learned predator recognition: An experimental test and framework for future studies. Proceedings of Royal Society B, 274: 1853-1859.

Ferrari, M. C. O., Wisenden, B. D. \& Chivers, D. P. (2010). Chemical ecology of predator-prey interactions in aquatic ecosystems: A review and prospectus. Canadian Journal of Zoology, 88: 698-724.

Johnson, D. D. P., Blumstein, D. T., Fowler, J. H. \& Haselton, M. G. (2013). The evolution of error: Error management, cognitive constraints, and adaptive decision-making biases. TRENDS in Ecology and Evolution, 28(8): 474-481.

Lima, S. L. \& Bednekoff, P. A. (1999). Temporal variation in danger drives antipredator behavior: The Predation Risk Allocation Hypothesis. The American Naturalist, 153(6): 649-659. Lima, S. L. \& Dill, L. M. (1990). Behavioral decisions made under the risk of predation - a review and prospectus. Canadian Journal of Zoology-Revue Canadienne De Zoologie, 68: 619-640.

Mateo, J. M. (2007). Ecological and hormonal correlates of antipredator behavior in adult Belding's ground squirrels (Spermophilus beldingi). Behavioral Ecology and Sociobiology, 62: 37-49. 
Munoz, N. E. \& Blumstein, D. T. (2012). Multisensory perception in uncertain environments. Behavioural Ecology, 23(3): 457-462.

Schmidt, K. A., Dall, S. R. \& van Gils, J. A. (2010). The ecology of information: An overview on the ecological significance of making informed decisions. Oikos, 119: 304-316.

Searcy, W. \& Nowicki, S. (Eds.). (2005). The Evolution of Animal Communication: Reliability and Deception in Signaling Systems. Princeton: Princeton University Press.

Sih, A. (1992). Prey uncertainty and the balancing of antipredator and feeding needs. American Society of Naturalists, 139(5): 1052-1069. 